\title{
WHAT IS THE NEED FOR BUILDING PARTS? - A comparison of CityGML, INSPIRE Building and a Swedish building standard
}

\author{
H. Eriksson ${ }^{1,2}$, L. Harrie ${ }^{2}$, J. M. Paasch ${ }^{1,3}$ \\ ${ }^{1}$ Lantmäteriet - the Swedish mapping, cadastral and land registration authority, Sweden - helen.eriksson@1m.se, \\ jesper.paasch@1m.se \\ ${ }^{2}$ Department of Physical Geography and Ecosystem Science - Lund University, Sweden - helen.eriksson@ nateko.lu.se, \\ lars.harrie@ nateko.lu.se \\ ${ }^{3}$ Department of Industrial Development, IT and Land Management - University of Gävle, Sweden - jesper.paasch@hig.se
}

KEY WORDS: Buildings, Building parts, CityGML, INSPIRE building, Svensk geoprocess, specifications, IFC

\begin{abstract}
:
The need for digital building information is increasing, both in the form of 3D city models (as geodata) and of more detailed building information models (BIM). BIM models are mainly used in the architecture, engineering and construction industry, but have recently become interesting also for municipalities. The overall aim of this paper is to study one way of dividing a building, namely the division of a building into building parts in both 3D city models and in BIM models. The study starts by an inventory of how building parts are defined in 3D city model standards (CityGML, the INSPIRE building specification and a Swedish national specification for buildings) and in BIM models (Industry Foundation Classes, IFC). The definition of building parts in these specifications are compared and evaluated. The paper also describes potential applications for the use of building parts, on what grounds a building could be divided into building parts, advantages and disadvantages of having building parts and what consequences it can have on the usage of the building information. One finding is that building parts is defined similar, but not identical in the studied geodata specifications and there are no requirements, only recommendations on how buildings should be divided into building parts. This can complicate the modelling, exchange and reuse of building information, and in a longer perspective, it would be desirable to have recommendations of how to define and use building parts in for example a national context.
\end{abstract}

\section{INTRODUCTION}

The use of $3 \mathrm{D}$ city models is increasing in society for a wide range of applications that need a digital representation of the urban environment. Alongside, the architecture, engineering and construction (AEC) industry, needs digital representations for planning, design and construction of buildings. In that field the development has gone from the drawing based CAD systems to the object based 3D Building Information Models (BIM). To be able to support construction, the BIM models are often very detailed. Some parts of these detailed BIM models are of interest for other actors. Recently, there has been a growing interest from municipalities to use BIM models in for example the building permit process and in $3 \mathrm{D}$ real property formation. The challenge here is how the BIM models can be used together with, and also strengthen, the municipality geodata.

The CityGML standard by the Open Geospatial Consortium, OGC, (Gröger et al. 2012) is the most comprehensive standard for exchange of 3D city models (Liu et al. 2017). Other specifications for 3D geodata buildings are the INSPIRE Buildings (BU) specification (2013), and in Sweden also the specification for buildings from Svensk geoprocess (SGP building, 2018), a governmental and municipal cooperative that serves data exchange at the regional level. The INSPIRE BU specification is influenced by the section in CityGML that describes buildings, and the Swedish specification SGP Building is influenced by CityGML, INSPIRE BU and other Swedish specifications. Most BIM models are still created using proprietary formats, but the use of the open ISO standard
Industry Foundation Classes (IFC, ISO 16739:2013, 2013) is increasing, judged by the number of published articles and conference presentations on the subject during recent years.

This paper concentrates on one of the possible ways of dividing a building feature, namely the division of a building into building parts. This classification is defined in the geodata specifications CityGML, INSPIRE BU and in SGP buildings, although the definitions vary slightly. The definition of building parts in SGP Building differ the most. Here, building parts play an important role as they are the only features that include the geometry of the building. The other specifications include the geometry on both buildings and building parts. The division of a building into smaller parts is also possible in IFC as an IfcBuilding can consist of several other IfcBuilding features.

Specifications of how to divide a building into building parts is required for facilitating the exchange of 3D building information. The SGP building specification is, for example, used both when municipalities exchange information with Lantmäteriet, (the the Swedish mapping, cadastral and land registration authority) and with the AEC industry. Having no recommendation on the use of building parts will result in a variety of models that can be difficult to both combine and exchange. Such specifications are also of interest for the integration of BIM data and geodata; the way one chooses to divide a building into smaller parts can affect the complexity of the transformation of data between models and also between standards (Isikdag and Zlatanova, 2009; de Laat and van Berlo, 2010; El-Mekawy et al. 2012 and Oldfield et al. 2017). 
Buildings can also be described at different levels of detail (LOD); the main motives for having these levels are that applications need different representations of the buildings. That is, the geometry, topology and semantics are described with varying complexity at the different levels of detail. Example of applications that need information in different LODs are design, modelling, reconstruction, emergency response, navigation and game development. The classification into LODs can also facilitate interoperability, since features with the same LOD could more easily be integrated.

All geodata specifications mentioned above define the LOD concept. The bases of these specifications are the CityGML definition that goes from a digital elevation model (LOD0) to a detailed representation of both the interior and exterior of a building (LOD4), but the details of the LOD definitions varies between the specifications. Biljecki et al. (2014) describe that the LOD concept in CityGML is ambiguous and that there is a need to refine the LODs. Benner et al. (2013) suggests an increase of the number of LODs from the five LODs defined in CityGML to eight exteriors and eight interior LODs. Also Biljecki et al. (2016) suggest an increase of the number of LODs and describes 16 LODs that are in line with the CityGML LODs and describe the exterior of buildings. The study also claims that it would be better to have requirements instead of recommendations in the LOD definitions.

There is a relation between building parts and LODs in the three described geodata specifications. The geometry for buildings (in CityGML and INSPIRE BU) and the geometry for building parts (in all three specifications) can be described in different LODs. That is, multiple representations of buildings and building parts can exist simultaneously. One thing that is not possible though is to have different number of building part at different LODs.

The aim of this paper is to twofold. The first aim is to study how building parts is defined in geodata and BIM specifications. The second aim is to describe potential applications for the use of building parts, on what grounds a building could be divided into building parts, advantages and disadvantages of having building parts and what consequences it can have on the usage of the building information.

The paper is organised as follows. Section two describes how building parts are defined in CityGML, INSPIRE BU, SGP Building and IFC, section three gives examples of potential applications for building parts and finally section four, discuss some findings and describes future work.

\section{BUILDING PARTS IN GEODATA AND BIM SPECIFICATIONS}

In the geodata specifications CityGML, INSPIRE BU and SGP building, there is a possibility to divide a building into building parts. The division is made when a building is not homogenous and Figure 1 shows four examples from the INSPIRE BU specification on reasons for performing such division. The division can be done due to physical aspects (Figure 1a height above ground, and $1 \mathrm{~b}$ number of floors above ground). A building that has different current use it can also be split (Figure 1c where part $\mathrm{A}$ is agriculture and part $\mathrm{B}$ residential), or if the temporal aspects for the building differ (Figure 1d where part A is constructed in 1920 and part B in 1950).
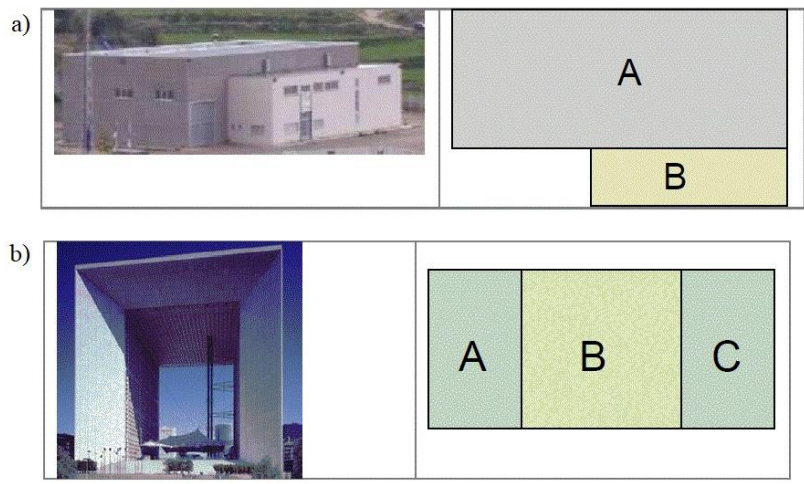

c)

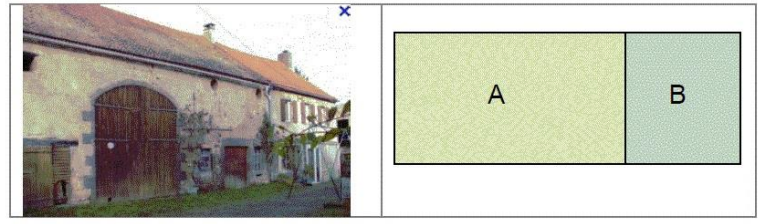

d)

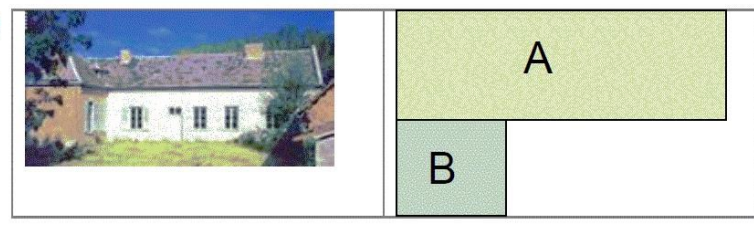

Figure 1. Building parts examples from the INSPIRE Building specification

In all geodata specifications, buildings and building parts inherit their properties from an abstract building feature type or aggregated building feature type (SGP building), but there are differences in the three approaches (Figure 2 and Figure 3)

Also in the IFC specification for BIM information there is a possibility to divide a building into parts, but here this is accomplished by a hierarchy of building features (Figure 4).

\subsection{CityGML}

CityGML describes that BuildingPart features are used to model structural parts of a building, for example different number of storeys or roof types.

There is an aggregate relation between the abstract building and the building part (Figure 2, left side). This "part-of" relation describes that BuildingParts can exist on its own, without being a part of a Building or another BuildingPart. The aggregation starts at_AbstractBuilding which implies that both Buildings and BuildingParts can consist of BuildingParts, that is, the relation is recursive. A BuildingPart should be uniquely related to exactly one Building or BuildingPart object, so there can either be a hierarchy of Building-BuildingPart features or a hierarchy of BuildingPart-BuildingPart features. 

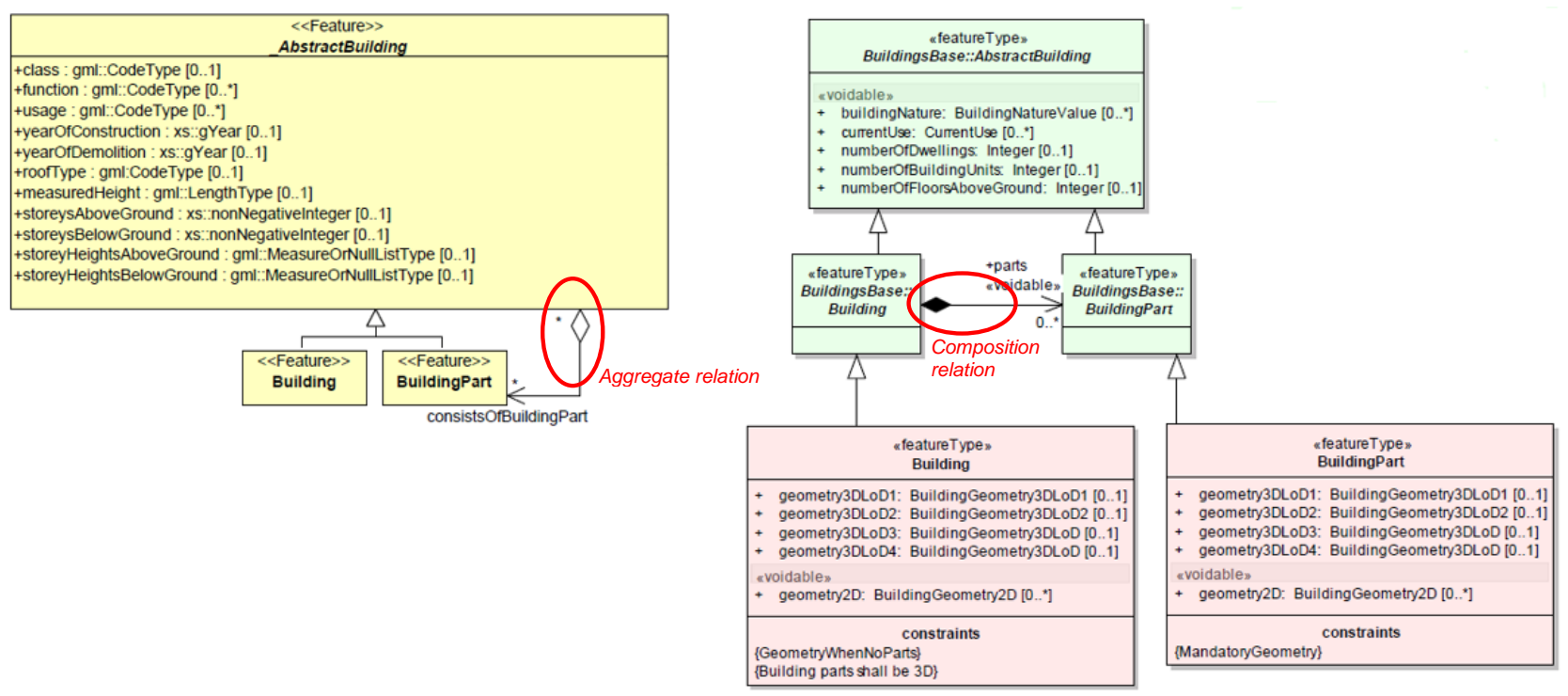

Figure 2. Building and building parts in CityGML (left) and INSPIRE Building (right)

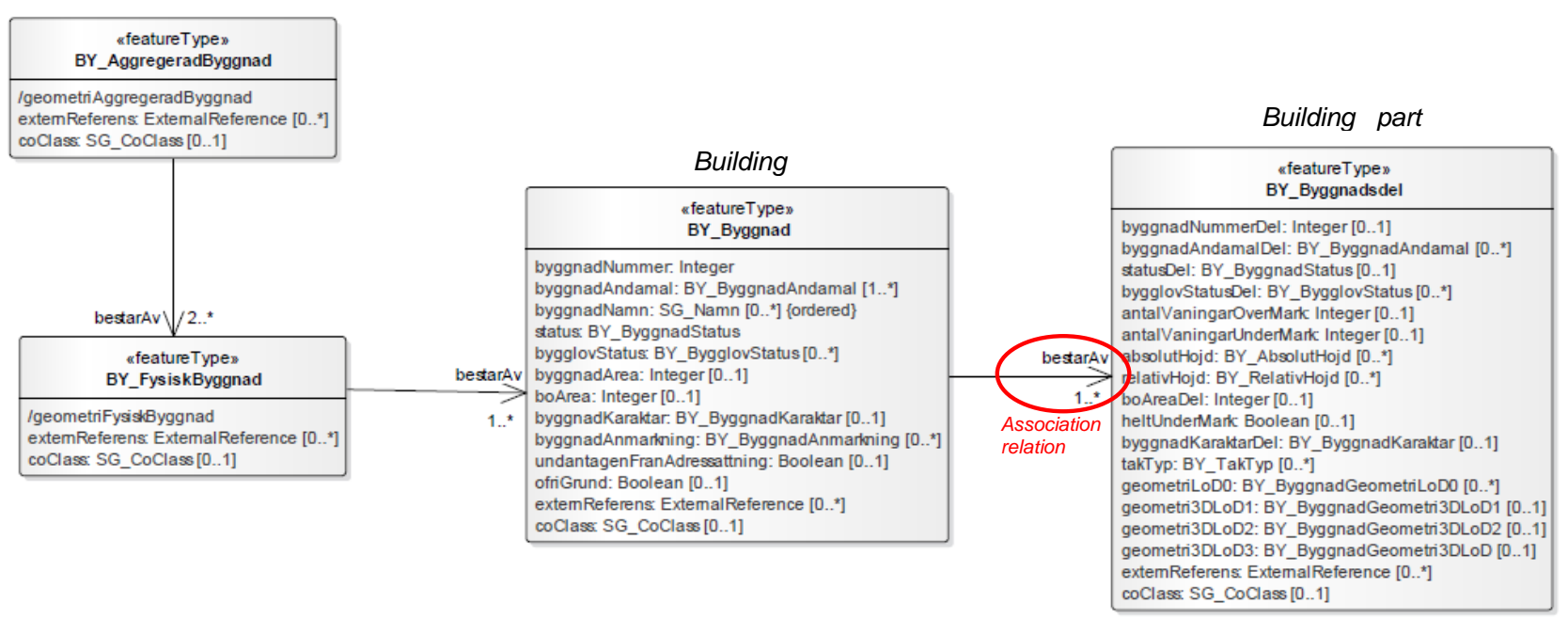

Figure 3. Building and building parts in Svensk geoprocess (SGP) building

\subsection{INSPIRE Building}

In the INSPIRE BU specification, it is described that BuildingParts can be used when a building is not homogenous, for example regarding attributes related to physical aspects (height above or below ground, number of floors above or underground or roof type), temporal aspects (year of construction) or functional aspects (building nature or current use).

CityGML (v2.0) has strongly influenced the development of the INSPIRE BU model, and there are many similarities but also some differences between the INSPIRE BU model and CityGML. One difference concerns the division of a building into building parts. In INSPIRE BU there is a composition relation between the Building and the BuildingPart (Figure 2, right side). It implies that a Building consists of one or many BuildingParts and that a BuildingPart cannot exist without the Building. This is a simplification of CityGML where the aggregation between building and building part is recursive. In INSPIRE BU, the composition relation starts at Building, therefore, there can only be a hierarchy of BuildingBuildingPart features.

A BuildingPart in INSPIRE BU has the following definition and description: A BuildingPart is a sub-division of a Building that might be considered itself as a building. A BuildingPart is homogeneous related to its physical, functional or temporal aspects. Building and BuildingPart share the same set of properties, for example a building may be composed of two building parts having different heights above ground.

\subsection{Svensk geoprocess building}

The SGP building specification defines a building part as a subdivision of a building that might consider itself as a building. A building part is homogeneous related to its physical or functional aspects (nothing is mentioned here about temporal aspects though). Recommendations for generalisation of information to the LODs are described, for example definitions of how big the differences in roof heights should be, and on how large a building part should be before describing it as a building part at a certain LOD. There is also a mentioning for 
LOD2 that "smaller building parts can be removed in the generalisation"

The specification for buildings in Svensk geoprocess is strongly influenced by both INSPIRE BU and CityGML with some differences, one of which is the division into building parts. In SGP buildings there is an association relation between building (BY_Byggnad) and building part (BY_Byggnadsdel), that is, no aggregation or composition relation as in CityGML and INSPIRE BU (Figure 3). As in INSPIRE BU, the relation starts at Building, so only hierarchies of Building-Building part features can exist. Another difference is that in SGP buildings, the geometry of the building is only defined on the building part features. This implies that all buildings with geometry must have at least one building part. The placement of the geometry on building parts in SGP building is influenced by how 2D buildings and building parts are currently treated in the registers at Lantmäteriet.

\subsection{IFC}

IFC does not include a specific building part feature, but an IfcBuilding can consist of other IfcBuildings (Figure 4). This hierarchic structure of IfcBuildings describes a division of a building into smaller parts, building sections. Such building section has the following definition: A building can also be decomposed in (vertical) parts, where each part defines a building section. This is similar to the division of a building into building parts as it is defined in the studied geodata specifications.

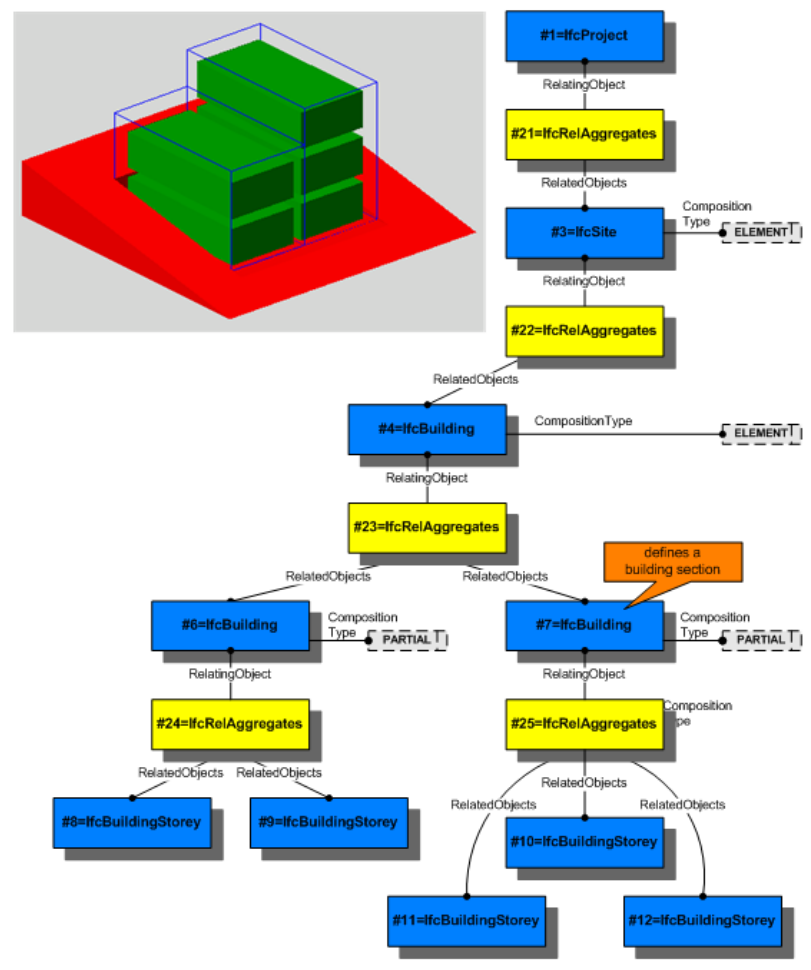

Figure 4. A hierarchy of building features in IFC (source: http://www.buildingsmart-tech.org/ifc)

\section{POTENTIAL APPLICATIONS FOR BUILDING PARTS}

There are some recommendations for when a building should be divided into building parts in the three geodata specifications described above. They all mention physical aspects (such as height above ground and roof type). Both INSPIRE BU and SGP building also mention the functional aspect (current use), while only INSPIRE BU includes the temporal aspect (year of construction). In addition to this, SGP building also gives recommendations on sizes etc. to use for generalisation of building parts into different LODs.

All the above are recommendations though, there are no requirements on when buildings must be divided into building parts. Therefore, the division is somewhat arbitrary and it is not clear when it can be an advantage and when can be a disadvantage to do so. The following sections describe some possible fields of application when building parts could be of use, or maybe are unsuitable. Most of the examples described are seen from the perspective of how geodata could be used at a municipality.

\subsection{Building permit process}

There is a growing interest to automate the building permit process and here, the integration of BIM data and geodata is central (Benner et al. 2010; van Berlo et al. 2013 and Olsson et al. 2018). In many cases, a building permit concerns an extension of the building. Such an extension can be treated as a new building part if it differs in for example height or roof type (physical aspects), will have a use that differ from the original building (functional aspect) and it will have a new year of construction (temporal aspect).

Even though an extension of a building conforms to the aspects described above, it is not clear whether such extension will be treated as a new building part or if the geometry of the existing building (or building part) will be extended as no rules, only recommendations exist. Building permits are primarily managed by municipalities and the division of buildings into building parts are often handled differently. How the division into building parts is conducted could in turn affect the continued use of the building information.

The use of building parts based on the building permit process is also linked to the collection method of building objects in a city model. Most commonly today is that the city models are collected by photogrammetric and laser-scanning techniques, but we could foresee that more building objects will be coming from BIM-models in the future (at least in the maintenance phase of a city model) (cf. section 3.4 below). In the latter case the city model is more naturally extended by building parts, as part of the building permit process.

\subsection{Real property formation in 3D}

During the last years, it has become more common to integrate 3D BIM information with cadastral information, especially for the creation of 3D parcels (Atazadeh et al. 2017 and Oldfield et al. 2017). One obstacle in this integration is that BIM describes buildings using physical spaces (rooms, corridors and walls) while the land registry is interested in legal spaces (the rights an owner can claim on a spatial unit), Kalogianni et al. 2017. 
There is no mentioning of the aspect of dividing buildings into building parts in any of the papers mentioned above, and it is unclear whether the division into building parts will affect the integration of 3D buildings and 3D cadastral information. Having building parts that reflects the use of the building (e.g. residential, industrial and commerce) could perhaps ease the legal division as there often are different owners on for example residential and commercial parts of a building. On the other hand, if the building parts reflect the physical aspects, it could be the opposite, the legal space could stretch over two or more building parts. If and in that case how the division into building parts will affect the integration of 3D building information and cadastral information still needs to be evaluated.

\subsection{Visualisation}

For visualisation purposes, there can be a need to have different number of building parts for different LODs. For example, in LOD0 and LOD1, where the building is represented as a footprint or as a cube, there is no need to divide the building into building parts. For LOD2, building parts that substantially differ in shape from the rest of the building could be included, whereas all building parts should be included in LOD3 and LOD4.

To have different number of building parts for different LODs is not possible in any of the described geodata standards. CityGML and INSPIRE BU have a work around for this as these specifications include the possibility to have geometry on both the building and the building part features. For example, two descriptions of the geometry for LOD2 could be accomplished by: having one simplified geometry excluding the geometric representation of building parts as a LOD2 geometry on the building feature; and LOD2 geometries of the building parts on each of the included building part features. This is not possible in the SGP building specification though, as the geometry can only be described on the building parts.

\subsection{Transformation from BIM buildings to geodata buildings}

3D BIM models are often seen as a possible source when 3D geodata building models are needed. It has therefore become increasingly common to transform BIM models to geodata models, and especially to transform IFC models to CityGML models. Even though there are many similarities between BIM and geodata, there are also many differences that can hamper the transformation. For example, there are differences in the representation of geometries and different types of coordinate systems are used (Isikdag and Zlatanova, 2009; Deng et al., 2016 and Liu et al., 2017). In IFC, LOD stands for Level of Development and in CityGML for Level of Detail, and the two LODs do not match (Deng et al., 2016). Also the structures differ; objects in IFC can be connected to each other in many ways and are not statically defined on the IFC schema level, while in CityGML, this is defined on the schema level and objects can only connect in a certain way (Isikdag and Zlatanova, 2009; de Laat and van Berlo, 2010 and El-Mekawy et al. 2012).

When an IFC building model that are divided into parts (building sections, see Figure 4) are transformed into a geodata building model, these building sections will most likely be transformed into building parts. We have not found any literature describing if and in that case how this could have any impact on the resulting geodata buildings. For example, does the division into building sections made in IFC correspond to the needs for building parts in the geodata community? If not, this is something that needs to be handled in the IFC model prior to the transformation.

\section{CONCLUDING REMARKS}

All geodata specifications, CityGML, INSPIRE BU and SGP building, include the concept of building parts in similar, but not identical ways. The Swedish SGP building specification is the one that differ the most as the geometry of the building can only be defined on the building part features, not on the building feature itself. The division of a building into smaller parts is also possible in the BIM standard IFC. It does not include a building part feature, but a building in IFC can consist of several other building features.

As 3D BIM models have the potential to be a source for $3 \mathrm{D}$ geodata buildings, the structure of the geodata model will most probably have the same hierarchic structure as the BIM model. This is also true for the division of a building into building parts. A question here is if this type of division of buildings into building parts suit the needs of the geodata community (for example municipalities).

Municipalities can divide 3D geodata buildings into building parts during for example the building permit process (where a new extension can become a building part) or to facilitate the 3D real property formation (by creating building parts based on the current use of the building, e.g. residential, industrial and commerce). Also here the question is what consequences the way a building is divided into building parts will have when the building information is used later on in a different context.

It can be discussed whether having different definitions of building parts in the geodata specifications are desirable or not. One solution could be to agree upon one definition or at least refine the definitions so they are more in line. This is especially true for the SGP building specification as this is a new specification that has not yet been implemented. To take this one step further, is it wise to use these three different geodata specifications for 3D buildings? Should we for example rather only use CityGML and create extensions of the CityGML specifications when additional information not included in CityGML is needed? (cf. studies by Tegtmeier et al., 2014; Nouvel et al., 2015; Li et al., 2016 and Eriksson et al., 2018) This is a big step that will probably not be possible, but to have clear recommendations (and if possible also requirements) of how to use building parts in a national context can be a first step in the right direction.

This paper studies how building parts are defined in geodata and BIM specifications and describes potential applications for the use of building parts. The next step in this research is to perform tests with 3D geodata building information to evaluate if and in that case how different ways of dividing a building into building parts (as well as having the geometry on the building or on the parts) would have any effect on e.g. building permit and $3 \mathrm{D}$ cadastre applications.

\section{ACKNOWLEDGEMENTS}

We would like to thank Lantmäteriet, the Swedish mapping, cadastral and land registration authority, Lund University and the University of Gävle for the financial support of this study. 


\section{REFERENCES}

Atazadeh, B., Rajabifard A., Kalantari M. (2017). Assessing Performance of Three BIM-Based Views of Buildings for Communication and Management of Vertically Stratified Legal Interests, ISPRS International Journal of Geo-Information, 6(7), 198 .

Benner, J., Geiger, A., Häfele, K.-H. (2010). Concept for Building Licensing Based on Standardized 3d Geo Information. In Proc. of the 5th International 3D GeoInfo Conference, http://misc.gis.tu-

berlin.de/3dgeoinfo/ISPRS_Conference_CD/Paper_ISPRS/Oral /2_3DGeoInfo2010_105_Benner_BuildingLicensing.pdf.

Benner, J., Geiger, A., Gröger, G., Häfele, K.H., Löwner, M.O., (2013). Enhanced LOD concepts for virtual 3D city models. ISPRS Ann. Photogramm. Remote Sens. Spatial Inf. Sci. II2/W1, pp. 51-61.

Biljecki, F., Ledoux, H., Stoter, J., Zhao, J. (2014). Formalisation of the level of detail in $3 \mathrm{D}$ city modelling, Environment and Urban Systems, 48, pp. 1-15.

Biljecki, F., Ledoux, H., Stoter, J. (2016). An improved LOD specification for 3D building models, Computers, Environment, and Urban Systems, 59, pp. 25-37.

de Laat, R., van Berlo, L. (2010). Integration of BIM and GIS: The development of the CityGML GeoBIM extension. Advances in 3D Geo-Information Sciences, pp. 211-225.

Deng Y., Cheng J.C.P., Anumba C. (2016). Mapping between BIM and 3D GIS in different levels of detail using schema mediation and instance comparison. Automation in Construction, 67, pp. 1-21.

Domínguez, B., García, Á.L, Feito, F.R., (2011). Semantic and topological representation of building indoors: an overview. The Joint ISPRS Workshop on $3 D$ City Modelling \& Applications and the 6th 3D GeoInfo Conference, Wuhan, China.

El-Mekawy M., Östman A., Hijazi I. (2012). A Unified Building Model for 3D Urban GIS. ISPRS International Journal of Geo-Information, 1, pp. 120-145.

Eriksson H., Harrie L., Paasch J. M., Persson A. (2018). Techniques for and consequences of using INSPIRE extensions: a case study with Swedish hydrological data. International Journal of Spatial Data Infrastructures Research, 13, pp. 172201 ,

http://ijsdir.jrc.ec.europa.eu/index.php/ijsdir/article/view/471.

Gröger G., T. H. Kolbe, C. Nagel, K-H. Häfele (2012). OGC City Geography Markup Language (CityGML) Encoding Standard v2. 0., OGC Doc, 12-019,

http://www.opengeospatial.org/standards/citygml, (28 June 2018).

INSPIRE (2014). Data Specification on Buildings - Technical Guidelines, Version 3.0, European Commission Joint Research Centre, http://inspire.ec.europa.eu/id/document/tg/bu, (28 June 2018).
Isikdag U., Zlatanova S. (2009). A SWOT analysis on the implementation of Building Information Models within the Geospatial Environment. Krek A, Rumor M, Zlatanova S, Fendel EM (eds) Urban and Regional Data Management UDMS Annual 2009, Taylor \& Francis Group, London, pp. 1530 .

ISO 16739:2013 (2013)., Industry Foundation Classes (IFC) for data sharing in the construction and facility management industries.

Li L., J. Wu, H. Zhu, X. Duan and F. Luo (2016). 3D modeling of the ownership structure of condominium units, Computers, Environment and Urban Systems 59, pp. 50-63.

Liu X., Wang X.Y., Wright G., Cheng J.C.P., Li X., Liu R. (2017). A State-of-the-Art Review on the Integration of Building Information Modeling (BIM) and Geographic Information System (GIS). ISPRS International Journal of GeoInformation 6, 53.

Nouvel R., J-M. Bahu, R. Kaden, J. Kaempf, P. Cipriano, M. Lauster, K-H. Haefele, E. Munoz, O. Tournaire, E. Casper (2015). Development of the CityGML Application Domain Extension Energy for Urban Energy Simulation, $14^{\text {th }}$ Conference of International Building Performance Simulation Association, Hyderabad, India.

Oldfield J., van Oosterom P., Beetz J., Krijnen T. F. (2017). Working with Open BIM Standards to Source Legal Spaces for a 3D Cadastre, ISPRS International Journal of GeoInformation, 6(11), 351.

Olsson, P., Axelsson, J., Hooper, M., Harrie, L. (2018). Automation of building permission by integration of BIM and geospatial data, (in press).

SGP Building (2018). Geodataspecifikation Byggnad, Version 3.0, http://www.lantmateriet.se/globalassets/omlantmateriet/var-samverkan-med-andra/svenskgeoprocess/specifikationer/sgp_geodataspecifikation_byggnad_ v3.0.pdf (28 June 2018).

Tegtmeier W., S. Zlatanova, P.J.M. van Oosterom and H.R.G.K. Hack (2014). 3D-GEM: Geo-echnical extension towards an integrated 3D information model for infrastructural development, Computers \& Geosciences, 64, pp. 126-135.

van Berlo, L., Dijkmans, T., Stoter, J. (2013). Experiment for integrating Dutch $3 \mathrm{~d}$ spatial planning and BIM for checking building permits. ISPRS Ann. Photogramm. Remote Sens. Spatial Inf. Sci. 2013, II-2/W1, pp. 279-284 https://www.isprs-ann-photogramm-remote-sens-spatial-infsci.net/II-2-W1/279/2013/isprsannals-II-2-W1-279-2013.pdf (28 June 2018). 